\title{
Engraftment of ES-Derived Myogenic Progenitors in a Severe Mouse Model of Muscular Dystrophy
}

\author{
Antonio Filareto\#, Radbod Darabi” and Rita C.R. Perlingeiro* \\ Lillehei Heart Institute, Department of Medicine, University of Minnesota, Minneapolis, MN \\ \#These authors contributed equally to this work
}

\begin{abstract}
Controlled myogenic differentiation of mouse embryonic stem cells by Pax3 combined with purification of PDGFaR+Flk-1- paraxial mesoderm results in the efficient in vitro generation of early skeletal myogenic progenitors. Upon transplantation into dystrophin-deficient $m d x$ mice, these progenitors promote significant regeneration that is accompanied by improvement in muscle contractility. In this study, we aimed to raise the bar and assess the therapeutic potential of these cells in a more clinically relevant model of muscular dystrophy: the dystrophin-utrophin double-knockout (dKO) mouse. Unlike $m d x$ mice, which display a mild phenotype, dKO mice are severely ill, displaying progressive muscle wasting, impaired mobility, and premature death. Here we show that in this very severe model of DMD, transplantation of Pax3-induced ES-derived skeletal myogenic progenitors results in significant engraftment as evidenced by the presence of Dystrophin+ myofibers with restoration of $\beta$-dystroglycan and eNOS within the sarcolemma, and enhanced strength of treated muscles. These findings demonstrate that ES-derived myogenic cell preparations are capable of engrafting in severely dystrophic muscle, and promote significant regeneration, providing a rationale for further studies on the potential therapeutic application of these cells in muscular dystrophies.
\end{abstract}

Keywords: Mouse ES cells; Muscular dystrophy; Utrophin; Dystrophin; mdx/utrn ${ }^{-/}$mice; Pax3; Regeneration.

\section{Introduction}

Duchenne Muscular Dystrophy (DMD), the most prevalent lethal genetic disorder in children, is an X-linked recessive disorder with an estimated incidence of 1 in 3500 live male newborns. DMD is caused by loss of dystrophin [1,2], a sarcolemma bound protein and member of the dystrophin-glycoprotein complex (DGC) that links the cytoskeleton to the extracellular matrix $[2,3]$. Lack of dystrophin leads to compromised sarcolemma integrity, apoptosis of muscle fibers, chronic tissue degeneration, and impaired muscle contractility [4]. The repeated cycles of degeneration and regeneration in dystrophic muscles result in exhaustion of its regenerative capacity, fibrosis, and eventual disruption of the muscle tissue architecture. Due to these effects, DMD patients exhibit progressive muscle wasting and atrophy, which leads to their being confined to a wheelchair before the age of 12 and to eventual death due to respiratory insufficiency [5]. To date there is no effective treatment for DMD patients.

Dystrophin mutant mice $(m d x)$ have been extensively used as a model for DMD [6], however they present a mild phenotype when compared to human DMD. This has been attributed to compensatory overexpression of the dystrophin-related protein, utrophin [7]. Accordingly, double knockout (dKO) mice lacking both dystrophin and utrophin present a severe phenotype, characterized by progressive muscle wasting, impaired mobility, abnormal breathing pattern, cardiomyopathy, and premature death $[8,9]$, a phenotype that much more closely resembles DMD in human patients. Because of the severe phenotype and sickness of this strain, very few studies have used this mouse model to study potential therapeutic strategies in DMD [10-13]. However such studies are essential if preclinical evidence is sought for the ability of myogenic progenitors to engraft in and regenerate severely dystrophic muscle.

We have previously shown that transplantation of Pax3-induced ES-derived myogenic progenitors into $m d x$ mice result in significant muscle engraftment [14]. Here we asked whether these skeletal myogenic progenitors would be able to promote in vivo regeneration in the severely dystrophic muscle of the $\mathrm{dKO}$ mouse. Our results provide a preclinical rational for the consideration of this strategy in human patients.

\section{Material and Methods}

\section{Growth and differentiation of iPax3 ES cells}

Mouse iPax3 ES cells were maintained and differentiated as described [14]. To induce Pax3 expression during EB differentiation, doxycycline (Sigma) was added to the cultures at $1 \mu \mathrm{g} / \mathrm{ml}$ beginning at day 2 of EB differentiation.

\section{FACS analysis and sorting of EB-derived cells}

EB cells were collected after a short incubation with Trypsin, washed twice, first with IMDM 10\% FBS and then with staining buffer (PBS 2\% FBS), suspended in the same buffer containing $0.25 \mu \mathrm{g} / 10^{6}$ cells of Fc block (Pharmingen). PE-PDGFaR and APC-Flk-1 conjugated antibodies (eBioscience) were added at $1 \mu \mathrm{g} / 10^{6}$ cells in $100 \mu \mathrm{l}$ of staining buffer, and incubated at $4^{\circ} \mathrm{C}$ for 30 minutes before washing with the same buffer. Stained cells were analyzed and sorted on a FACS Aria (Becton-Dickinson) after addition of propidium iodide (Pharmingen) to exclude dead cells.

\section{Expansion of myogenic progenitors}

Sorted cells were cultured onto fresh gelatin-coated flasks in the

*Corresponding author: Rita C.R. Perlingeiro PhD, Lillehei Heart Institute, University of Minnesota, 4-124 Nils Hasselmo Hall, 312 Church St SE, Minneapolis, MN 55455 USA, Tel: 612625 4984; Fax: 612624 8118; E-mail: perli032@umn.edu

Received December 02, 2011; Accepted January 04, 2012; Published January 06, 2012

Citation: Filareto A, Darabi R, Perlingeiro RCR (2012) Engraftment of ES-Derived Myogenic Progenitors in a Severe Mouse Model of Muscular Dystrophy. J Stem Cell Res Ther S10:001. doi:10.4172/2157-7633.S10-001

Copyright: $\odot 2012$ Filareto A, et al. This is an open-access article distributed under the terms of the Creative Commons Attribution License, which permits unrestricted use, distribution, and reproduction in any medium, provided the original author and source are credited. 
presence of proliferation myogenic medium. This medium consisted of IMDM, 15\% FBS, 1\% Chicken Embryo Extract, 10\% horse serum, supplemented with $1 \mu \mathrm{g} \mathrm{ml}^{-1}$ of doxycycline and $5 \mathrm{ng} \mathrm{ml}^{-1}$ of bFGF.

\section{Transplantation studies}

All animals were handled in strict accordance with good animal practice as defined by the relevant national and/or local animal welfare bodies, and all animal work was approved by the University of Minnesota Institutional Animal Care and Use Committee. 4 week-old $\mathrm{dKO}: \mathrm{mdx} / \mathrm{utrn}^{- \text {- }}$ dystrophic mice model $(\mathrm{n}=5)$ were used for the in vivo studies. Myogenic progenitors from iPax 3 cell line $\left(5 \times 10^{5}\right.$ cells $/ 10 \mu l$ PBS) were injected into left TA muscles, while the right leg received the same volume of PBS as a negative control. Before intramuscular cell transplantation, mice received immunosuppression (FK-506/ tacrolimus) daily, as described [14].

\section{Immunofluorescence staining of tissue sections}

Engrafted muscles were frozen in isopentane- cooled in liquid nitrogen. Serial $10 \mu \mathrm{m}$ cryosections were collected and stained for Dystrophin and representative components of the DGC. For immunofluorescence staining, cut tissue were blocked for $1 \mathrm{~h}$ with $3 \%$ BSA, $2 \%$ goat serum and $0.05 \%$ Tween-20, then incubated with primary antibodies including anti-Dystrophin (1:250, Abcam), anti$\beta$-Dystroglycan (1:200) (H-242 sc-28535 Santa Cruz); and anti-nNOS (1:100) (Sigma), in PBS containing $2 \%$ goat serum. For secondary staining, a goat anti-rabbit-alexa-555 (1:1000) was used (Molecular Probes) and sections were incubated for 45 minutes at room temperature in PBS. DAPI (1:5000, 4,6-diamidino-2-phenylindole; Fluka) was used to counter-stain nuclei.

\section{Muscle preparation for mechanical studies}

For the measurement of contractile properties, mice were anaesthetized with avertin $(250 \mathrm{mg} / \mathrm{kg}$ I.P. $)$ and intact tibialis anterior (TA) muscles were dissected and placed in an experimental organ bath filled with mammalian Ringer solution containing (mM): $\mathrm{NaCl} 120.5$; $\mathrm{NaHCO} 3$ 20.4; glucose 10; $\mathrm{KCl} 4.8 ; \mathrm{CaCl} 2$ 1.6; MgSO 4 1.2; NaH2PO4 1.2; pyruvate 1.0 , adjusted to $\mathrm{pH} 7.4$. The chamber was perfused continuously with $95 \% \mathrm{O} 2-5 \% \mathrm{CO} 2$ and maintained at a temperature of $25^{\circ} \mathrm{C}$. The muscles were stimulated by an electric field generated between two platinum electrodes placed longitudinally on either side of the muscle (Square wave pulses $25 \mathrm{~V}, 0.2 \mathrm{~ms}$ in duration, $150 \mathrm{~Hz}$ ). Muscles were adjusted to the optimum length $(L o)$ for the development of isometric twitch force and a 5 min recovery period was allowed between stimulations. Optimal muscle length ( $L o$ ) and stimulation voltage $(25 \mathrm{~V})$ were determined from micromanipulation of muscle length and a series of twitch contractions that produced maximum isometric twitch force. In brief, after determination of optimal muscle length $(L o)$ and measurement of maximum isometric tetanic force, total muscle fiber cross-sectional area (CSA) was calculated by dividing muscle mass (milligram) by the product of fiber length (millimeter) and $1.06 \mathrm{mg} / \mathrm{mm}^{3}$, the density of mammalian skeletal muscle. Specific force $(s F o)$ was determined by normalizing maximum isometric tetanic force to CSA.

\section{Statistical analysis}

Differences between samples were assessed by using the Student's two-tailed $t$ test for independent samples.

\section{Results}

Proliferating skeletal myogenic progenitors were isolated from Pax3-induced differentiating ES cells following FACS purification for PDGFaR ${ }^{+}$Flk-1; , as previously described [14]. $5 \times 10^{5}$ cells were transplanted into the left tibialis anterior muscles of 4 -week old dystrophin/utrophin double knockout (dKO) mice, while the right TA muscles received only PBS (control). After 30 days, muscles were harvested and analyzed by immunofluorescence to assess engraftment as well as contractility. During this period, mice received daily injection of tacrolimus, an immunosuppressive agent, to prevent rejection of allogeneic cells.

As observed in Figure 1, whereas PBS-injected dKO mice presented only sporadic revertant dystrophin ${ }^{+}$myofibers (Figure 1A,C), muscles that had been transplanted with Pax3-induced ES-derived myogenic progenitors exhibited considerable numbers of myofibers expressing dystrophin (Figure 1B,D). Transplanted muscles from dKO mice contained about $12.3 \pm 1.4 \%$ of Dystrophin ${ }^{+}$myofibers (Figure 2).

An interesting feature of the $\mathrm{dKO}$ mouse is that the absence of dystrophin and utrophin leads to the depletion from the sarcolemma of members of the dystrophin-glycoprotein complex (DGC), namely $\beta$-dystroglycan ( $\beta$-DG) and $\alpha 1$-syntrophin ( $\alpha 1$-SYN), $[8,9,15]$, as well as neuronal nitric oxide synthase (nNOS) $[8,9,15]$. By analyzing serial sections of transplanted muscles, we observed recovery of $\beta$-DG and nNOS in the sarcolemma of engrafted Dystrophin ${ }^{+}$myofibers (Figure 3). This indicates that ES-derived myogenic precursors are able to promote regeneration in a severe model of $\mathrm{DMD}$, and to restore components of the DGC.

To assess whether engraftment was accompanied by functional improvement of dystrophic muscles, we measured the contractile properties of transplanted- and control PBS-injected TA muscles. Whereas no changes were observed in CSA and weight of treated muscles (Figure 4E-F, respectively), there was a significant improvement in maximal isometric tetanic and specific force (Figure 4A-D) in $\mathrm{dKO}$ transplanted muscles. As expected, despite significant improvement when compared to untreated $\mathrm{dKO}$ muscles (2-fold), absolute force did not reach wild-type levels after a single intra-muscular injection of ES-derived myogenic progenitors $\left(\mathrm{sF} 0=50 \mathrm{KN} / \mathrm{m}^{2}\right.$ vs $140 \mathrm{KN} / \mathrm{m}^{2}$ in transplanted $\mathrm{dKO}$ and age-matched $\mathrm{Bl} 6$ mice, respectively).

\section{Discussion}

Multiple approaches aiming to ameliorate the DMD phenotype have been intensively investigated using the $m d x$ mouse model, including gene therapy, exon skipping and cell-based therapy. In terms of gene therapy, recombinant adeno-associated viruses (rAAV) have shown good potential to deliver the missing gene [16], with AAV1, AAV2, AAV6, and AAV8 serotypes being the most effective for transducing skeletal muscle [17-18]. Although both safety and efficacy of administration to multiple limbs remain to be determined, one major limitation of this approach is the immune response of the host against the viral capsid. In fact, several groups have reported a strong T-cell mediated response to AAV2, 6, 8 and 9 [19-22].

Antisense-induced exon-skipping is a post-transcriptional strategy that directly restores the dystrophin reading frame for certain mutations. Two chemical classes of antisense oligonucleotides (AOs) are currently being investigated: 2'O-methyl-ribooligonucleosidephoshophorothioate $\left(2^{\prime} \mathrm{OMe}\right)$ and phosphorodiamidate morpholino oligomers (PMOs) $[23,24]$. This strategy has entered clinical trials, and preliminary results are encouraging [25]. However, the exon-skipping 
Citation: Filareto A, Darabi R, Perlingeiro RCR (2012) Engraftment of ES-Derived Myogenic Progenitors in a Severe Mouse Model of Muscular Dystrophy. J Stem Cell Res Ther S10:001. doi:10.4172/2157-7633.S10-001

strategy is very mutation-specific: the current oligos can be used only on a restricted group of patients that carry mutations that cause a reading frame change without a stop codon generated upstream of the targeted exon. In addition, because the lifetime of AOs is limited in vivo, patients may need to be re-injected weekly or monthly to maintain function levels of dystrophin [26]. In addition, as the leakiness of the
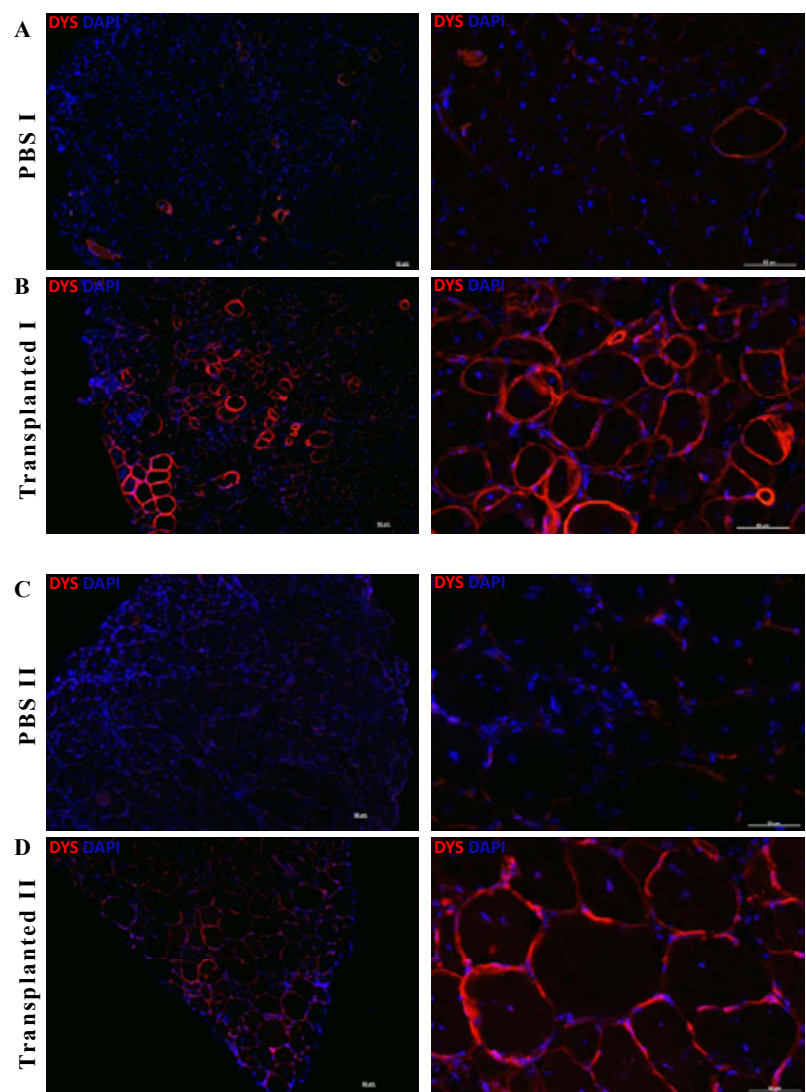

Figure 1: Engraftment potential of ES-derived myogenic precursors following transplantation in the dKO:mdx/utrn ${ }^{-1}$ dystrophic mouse model. Cryosections from TA muscles of two representative mice show staining with dystrophin antibody in muscles that had been injected with PBS (A, C) or myogenic progenitors $(B, D)$. DYSTROPHIN and DAPI are shown respectively in red, and blue. Scale bar is $50 \mu \mathrm{m}$.

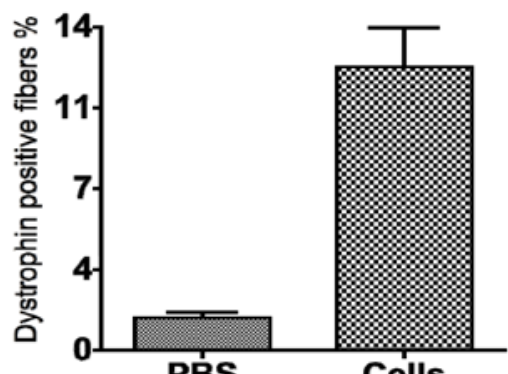

Figure 2: Dystrophin quantification in transplanted muscles. Cell engraftment was quantified using NIH Image J software. For PBS control groups, we examined random sections. For engrafted TA muscle, 3-4 representative cross-sections at $2 \mathrm{~mm}$ intervals were counted. Bars represent average percentage of DYS ${ }^{+}$myofibers per analyzed TA muscle. Error bars represent S.D.
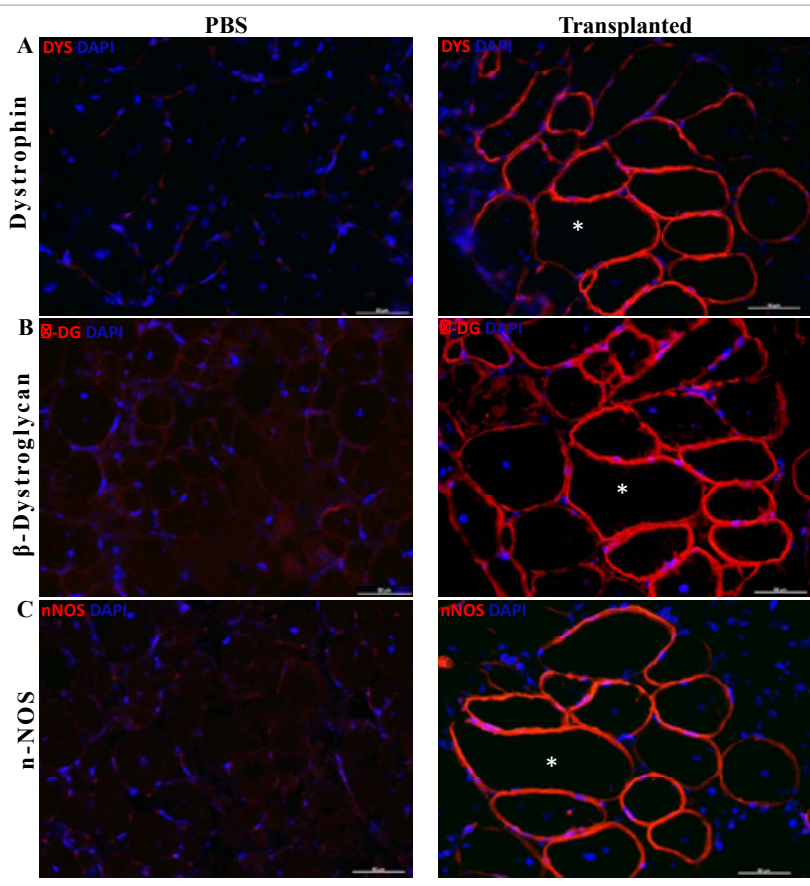

Figure 3: Immunofluorescence analyses of several members of the Dystrophin-related Glycoprotein Complex (DGC). Serial sections of both PBS-injected (left panels) and transplanted (right panels) muscles were stained with antibodies to Dystrophin (A), $\beta$-Dystroglycan (B), and n-NOS (C) antibodies. Expression of $\beta$-Dystroglycan and $n-N O S$ could be detected in $\mathrm{DYS}^{+}$myofibers.
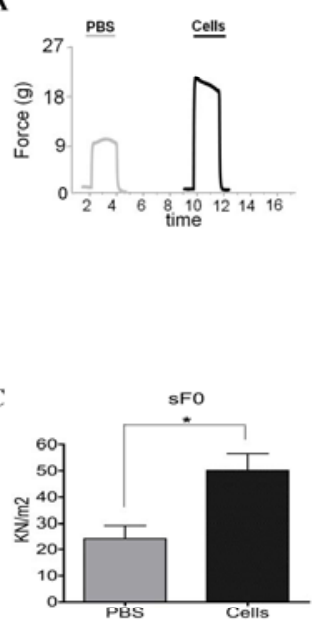

E

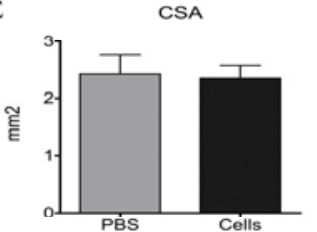

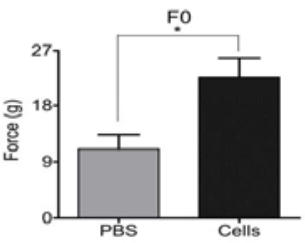

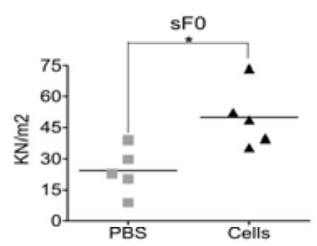

$\mathbf{F}$

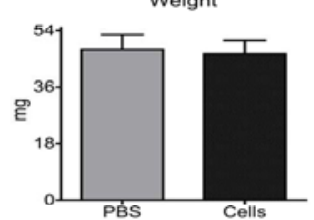

Figure 4: Cell transplantation of ES-derived myogenic precursors improves contractility of dKO:mdx/utrn ${ }^{-1}$ dystrophic mouse model. (A) Representative examples of isometric force-tracking in tibialis anterior (TA) muscles that had been injected with cells or PBS (black and gray lines, respectively). (B-D) Effect of cell transplantation on absolute (F0) (B), and specific sF0 (sF0=F0 normalize to $C S A$ ) force $(C, D)$. Average CSA (E) and weight $(F)$ of analyzed muscles. Error bars represent S.E.M. from a total of 5 transplanted mice ${ }^{*} p<0.01$ 
DMD mutant fibers is repaired, the ability of the AO to penetrate is diminished.

As an alternative to viral gene therapy and exon skipping, several studies have investigated the potential of cell-based therapies in DMD. Numerous cell preparations have been assessed for their regenerative potential. Despite initial excitement following the transplantation of adult myoblasts into $m d x$ mice [27-29], infusion of these cells into DMD patients in early clinical trials led to unsatisfactorily results [30-33], which has been ascribed to the poor survival and the limited migratory ability of injected myoblasts $[28,34]$.

Other groups have investigated whether bone marrow (BM) transplantation would ameliorate the dystrophic phenotype. Although some recruitment of donor-derived cells was found in the muscle of transplanted $m d x$ mice, levels of engraftment were quite low [35-37]. This was also the case when human marrow stromal cells (MSCs) were transplanted into dystrophic mice [38]. Although a somewhat better engraftment was observed when Pax3-transduced MSCs were injected when compared to non-transduced controls, neither engraftment was accompanied by functional improvement [38], and most likely would not provide functional benefit to DMD patients.

In addition to myoblasts, as described above, various other cell populations isolated from adult muscle have been described to possess regenerative potential, including muscle-derived stem cells (MDSCs) [39-41], mesoangioblasts or pericytes [42,43], and the most obvious candidate, the muscle stem cells known as satellite cells $[44,45]$. All of these fractions have been reported to produce significant engraftment when transplanted into dystrophic mice, and in the case of mesoangioblasts, this was also shown in dystrophic dogs. Because of these encouraging results in larger animals, phase 1 clinical trials are ongoing with donor-derived mesoangioblasts. The major caveat of primary cells is the limited cell number and the senescence associated with in vitro expansion.

ES and iPS cells [46] are pluripotent, and thus they represent an unlimited source of myogenic precursors [14,47-50]. However because skeletal myogenic differentiation from ES/iPS cells is inefficient, we have applied induction of Pax3 or Pax7 to these cells, which leads to the efficient proliferation of skeletal myogenic precursors. Upon transplantation, they are able to form new myofibers and seed the satellite cell compartment [14,47-48]. Besides Pax3 and Pax7, others myogenic transcription factors such as MyoD [51,52] and Myf5 [53] have been used to derive muscle cells from different sources in vitro. Overexpression of $\mathrm{MyoD}$ has also been used to potentiate the myogenic differentiation of mesoangioblasts [54]. However, only Pax3 and Pax7 have been shown to derive a proliferating population of skeletal myogenic precursors from ES cells with the capacity to engraft the satellite cell compartment. Conversely, forced MyoD expression in myoblasts promotes formation of multinucleate myotubes impairing in vitro expansion [52].

The findings shown here indicate that even in a very hostile environment, as in the $\mathrm{dKO}$ mouse model, ES-derived myogenic progenitors have the ability to engraft, to contribute to dystrophin ${ }^{+}$ myofibers and to ameliorate the dystrophic phenotype.

\section{Acknowledgements}

The project was supported by NIH grants RC1AR058118 and AR055299 (RCRP), the Muscular Dystrophy Center Core Laboratories P30-AR0507220, the Dr. Bob and Jean Smith Foundation (RCRP), and the Greg Marzolf Jr. Foundation (AF). We thank Jacquelyn Catanese for technical assistance.

\section{Authorship Statement Contribution}

A.F. and R.D. designed and conducted experiments, performed final analysis of the data and contributed to writing the paper. R.C.R.P. supervised the overall project, designed experiments, analyzed the data and wrote the paper.

\section{References}

1. Koenig M, Hoffman EP, Bertelson CJ, Monaco AP, Feener C, et al. (1987) Complete cloning of the Duchenne muscular dystrophy (DMD) cDNA and preliminary genomic organization of the DMD gene in normal and affected individuals. Cell 50: 509-517.

2. Hoffman EP, Brown RHJ, Kunkel LM (1987) Dystrophin: the protein product of the Duchenne muscular dystrophy locus. Cell 51: 919-928.

3. Dalkilic I, Kunkel LM (2003) Muscular dystrophies: genes to pathogenesis. Curr Opin Genet Dev 13: 231-238.

4. Cohn RD, Campbell KP (2000) Molecular basis of muscular dystrophies. Muscle Nerve 23: 1456-1471.

5. Emery AE (2002) The muscular dystrophies. Lancet 359: 687-695.

6. Bulfield G, Siller WG, Wight PA, Moore KJ (1984) X chromosome-linked muscular dystrophy ( $\mathrm{mdx}$ ) in the mouse. Proc Natl Acad Sci U S A 81: 11891192.

7. Matsumura K, Ervasti JM, Ohlendieck K, Kahl SD, Campbell KP (1992) Association of dystrophin-related protein with dystrophin-associated proteins in mdx mouse muscle. Nature 360: 588-591.

8. Deconinck AE, Rafael JA, Skinner JA, Brown SC, Potter AC, et al. (1997) Utrophin-dystrophin-deficient mice as a model for Duchenne muscular dystrophy. Cell 90: 717-727.

9. Grady RM, Teng H, Nichol MC, Cunningham JC, Wilkinson RS, et al. (1997) Skeletal and cardiac myopathies in mice lacking utrophin and dystrophin: a model for Duchenne muscular dystrophy. Cell 90: 729-738.

10. Ishizaki M, Maeda Y, Kawano R, Suga T, Uchida Y, et al. (2011) Rescue from respiratory dysfunction by transduction of full-length dystrophin to diaphragm via the peritoneal cavity in utrophin/dystrophin double knockout mice. Mol Ther 19: $1230-1235$.

11. Crisp A, Yin H, Goyenvalle A, Betts C, Moulton HM, et al. (2011) Diaphragm rescue alone prevents heart dysfunction in dystrophic mice. Hum Mol Genet 20: 413-421.

12. Goyenvalle A, Babbs A, Powell D, Kole R, Fletcher S, et al. (2010) Prevention of dystrophic pathology in severely affected dystrophin/utrophin-deficient mice by morpholino-oligomer-mediated exon-skipping. Mol Ther 18: 198-205.

13. Kawano R, Ishizaki M, Maeda Y, Uchida Y, Kimura E, et al. (2008) Transduction of full-length dystrophin to multiple skeletal muscles improves motor performance and life span in utrophin/dystrophin double knockout mice. Mol Ther 16: 825-831.

14. Darabi R, Gehlbach K, Bachoo RM, Kamath S, Osawa M, et al. (2008) Functional skeletal muscle regeneration from differentiating embryonic stem cells. Nat Med 14: 134-143.

15. Ohlendieck K, Campbell KP (1991) Dystrophin-associated proteins are greatly reduced in skeletal muscle from mdx mice. J Cell Biol 115: 1685-1694.

16. Blankinship MJ, Gregorevic P, Chamberlain JS (2006) Gene therapy strategies for Duchenne muscular dystrophy utilizing recombinant adeno-associated virus vectors. Mol Ther 13: 241-249.

17. Williams DA, Baum C (2003) Medicine. Gene therapy--new challenges ahead. Science 302: 400-401

18. Muller K, Heller H, Doerfler W (2001) Foreign DNA integration Genome-wide perturbations of methylation and transcription in the recipient genomes. J Bio Chem 276: 14271-14278

19. Wang Z, Zhu T, Qiao C, Zhou L, Wang B, et al. (2005) Adeno-associated virus serotype 8 efficiently delivers genes to muscle and heart. Nat Biotechnol 23 321-328.

20. Xiao W, Chirmule N, Berta SC, McCullough B, Gao G, et al. (1999) Gene therapy vectors based on adeno-associated virus type 1. J virol 73: 3994-4003.

21. Gregorevic P, Blankinship MJ, Allen JM, Crawford RW, Meuse L, et al. (2004) Systemic delivery of genes to striated muscles using adeno-associated vira vectors. Nat med 10: 828-834. 
Citation: Filareto A, Darabi R, Perlingeiro RCR (2012) Engraftment of ES-Derived Myogenic Progenitors in a Severe Mouse Model of Muscular Dystrophy. J Stem Cell Res Ther S10:001. doi:10.4172/2157-7633.S10-001

22. Foster K, Foster H, Dickson JG (2006) Gene therapy progress and prospects: Duchenne muscular dystrophy. Gene Ther 13: 1677-1685.

23. Kinali M, Arechavala-Gomeza V, Feng L, Cirak S, Hunt D, et al. ( 2009) Loca restoration of dystrophin expression with the morpholino oligomer AVI-4658 in Duchenne muscular dystrophy: a single-blind, placebo-controlled, doseescalation, proof-of-concept study. Lancet Neurol 8: 918-928.

24. van Deutekom JC, Janson AA, Ginjaar IB, Frankhuizen WS, Aartsma-Rus A, et al. (2007) Local dystrophin restoration with antisense oligonucleotide PRO051. N Engl J med 357: 2677-2686.

25. Hoffman EP, Bronson A, Levin AA, Takeda S, Yokota T, et al. (2011) Restoring dystrophin expression in duchenne muscular dystrophy muscle progress in exon skipping and stop codon read through. Am J pathol 179: 12-22.

26. Goyenvalle A, Seto JT, Davies KE, Chamberlain J (2011) Therapeutic approaches to muscular dystrophy. Hum Mol Genet 20: R69-78.

27. Brussee V, Tardif F, Roy B, Goulet M, Sebille A, et al. (1999) Successful myoblast transplantation in fibrotic muscles: no increased impairment by the connective tissue. Transplantation 67: 1618-1622.

28. Gussoni E, Blau HM, Kunkel LM (1997) The fate of individual myoblasts after transplantation into muscles of DMD patients. Nat med 3: 970-977.

29. Partridge TA, Morgan JE, Coulton GR, Hoffman EP, Kunkel LM (1989) Conversion of $\mathrm{mdx}$ myofibers from dystrophin-negative to positive by injection of normal myoblasts. Nature 337: 176-179.

30. Mendell JR, Kissel JT, Amato AA, King W, Signore L, et al. (1995) Myoblast transfer in the treatment of Duchenne's muscular dystrophy. N Engl J Med 333 832-838.

31. Partridge T, Lu QL, Morris G, Hoffman E (1998) Is myoblast transplantation effective? Nat med 4: 1208-1209.

32. Tremblay JP, Malouin F, Roy R, Huard J, Bouchard JP, et al. (1993) Results of a triple blind clinical study of myoblast transplantations without immunosuppressive treatment in young boys with Duchenne muscula dystrophy. Cell Transplant 2: 99-112.

33. Vilquin JT (2005) Myoblast transplantation: clinical trials and perspectives. Acta myology 24: 119-127.

34. Qu Z, Balkir L, van Deutekom JC, Robbins PD, Pruchnic R, et al. (1998) Development of approaches to improve cell survival in myoblast transfer therapy. J cell biol 142: 1257-1267.

35. Bittner RE, Schofer C, Weipoltshammer K, Ivanova S, Streubel B, et al. (1999) Recruitment of bone-marrow-derived cells by skeletal and cardiac muscle in adult dystrophic mdx mice. Anat Embryol (Berl) 199: 391-396.

36. Fukada S, Miyagoe-Suzuki Y, Tsukihara H, Yuasa K, Higuchi S, et al. (2002) Muscle regeneration by reconstitution with bone marrow or fetal liver cells from green fluorescent protein-gene transgenic mice. J Cell Sci 115: 1285-1293.

37. Gussoni E, Soneoka Y, Strickland CD, Buzney EA, Khan MK, et al. (1999) Dystrophin expression in the $\mathrm{mdx}$ mouse restored by stem cell transplantation. Nature 401: 390-394.

38. Gang EJ, Darabi R, Bosnakovski D, Xu Z, Kamm KE, et al. (2008) Engraftment of mesenchymal stem cells into dystrophin-deficient mice is not accompanied by functional recovery. Exp Cell Res 315: 2624-2636.
39. Qu-Petersen Z, Deasy B, Jankowski R, Ikezawa M, Cummins J, et al. (2002) Identification of a novel population of muscle stem cells in mice: potential for muscle regeneration. J Cell Biol 157: 851-864.

40. Wu X, Wang S, Chen B, An X (2010) Muscle-derived stem cells: isolation, characterization, differentiation, and application in cell and gene therapy. Cell Tissue Res 340: 549-567.

41. Cerletti M, Jurga S, Witczak CA, Hirshman MF, Shadrach JL, et al. (2008) Highly efficient, functional engraftment of skeletal muscle stem cells in dystrophic muscles. Cell 134: 37-47.

42. Sampaolesi M, Torrente Y, Innocenzi A, Tonlorenzi R, D’Antona G, et al. (2003) Cell therapy of alpha-sarcoglycan null dystrophic mice through intra-arterial delivery of mesoangioblasts. Science 301: 487-492.

43. Sampaolesi M, Blot S, D’Antona G, Granger N, Tonlorenzi R, et al. (2006) Mesoangioblast stem cells ameliorate muscle function in dystrophic dogs. Nature 444: 574-579.

44. Montarras D, Morgan J, Collins C, Relaix F, Zaffran S, et al. (2005) Direct isolation of satellite cells for skeletal muscle regeneration. Science 309: 2064 2067.

45. Sherwood RI, Christensen JL, Conboy IM, Conboy MJ, Rando TA, et al. (2004 Isolation of adult mouse myogenic progenitors: functional heterogeneity of cells within and engrafting skeletal muscle. Cell 119: 543-554.

46. Takahashi K, Yamanaka S (2006) Induction of pluripotent stem cells from mouse embryonic and adult fibroblast cultures by defined factors. Cell 126 : 663-676

47. Darabi R, Santos FNC, Filareto A, Pan W, Koene R, et al. (2011) Assessmen of the Myogenic Stem Cell Compartment Following Transplantation of Pax3/ Pax7-Induced Embryonic Stem Cell-Derived Progenitors. Stem cells 29: 777 790

48. Darabi R, Pan W, Bosnakovski D, Baik J, Kyba M, et al. (2011) Functiona Myogenic Engraftment from Mouse iPS Cells. Stem Cell Rev 7: 948-957.

49. Mizuno Y, Chang H, Umeda K, Niwa A, Iwasa T, et al. (2010) Generation of skeletal muscle stem/progenitor cells from murine induced pluripotent stem cells. FASEB J 24: 2245-2253.

50. Quattrocelli M, Palazzolo G, Floris G, Schoffski P, Anastasia L, et al. (2011) Intrinsic cell memory reinforces myogenic commitment of pericyte-derived iPSCs. J pathol 223: 593-603.

51. Weintraub H, Tapscott SJ, Davis RL, Thayer MJ, Adam MA, et al. (1989) Activation of muscle-specific genes in pigment, nerve, fat, liver, and fibroblast cell lines by forced expression of MyoD. Proc Natl Acad Sci U S A 86: 54345438 .

52. Watanabe S, Hirai H, Asakura Y, Tastad C, Verma M, et al. (2011) MyoD gene suppression by Oct4 is required for reprogramming in myoblasts to produce induced pluripotent stem cells. Stem cells 29: 505-516.

53. lacovino M, Bosnakovski D, Fey H, Rux D, Bajwa G, et al. (2011) Inducible cassette exchange: a rapid and efficient system enabling conditional gene expression in embryonic stem and primary cells. Stem cells 29: 1580-1588.

54. Tedesco FS, Hoshiya H, D'Antona G, Gerli MF, Messina G, et al. (2011) Stem cell-mediated transfer of a human artificial chromosome ameliorates muscula dystrophy. Sci Transl Med 3: 96ra78.
This article was originally published in a special issue, Embryonic and Induced Pluripotent Stem Cells handled by Editor(s). Dr. Jianlong Wang, Mount Sinai School of Medicine, United States 